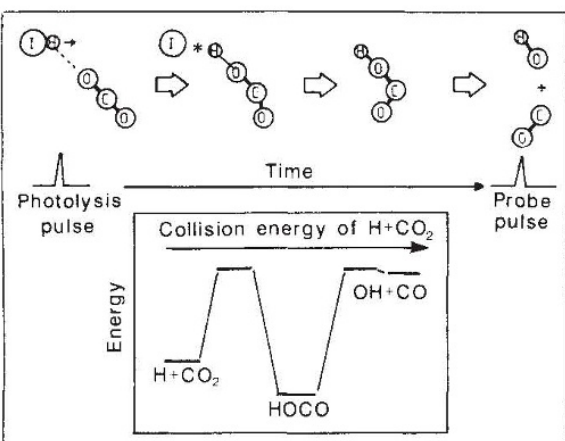

Fig. 2 Picosecond probing of the formation of $\mathrm{OH}$ in the reaction of $\mathrm{H}$ atoms with $\mathrm{CO}$. One picosecond laser pulse breaks the $\mathrm{HI}$ bond in a weakly bound $\mathrm{IH}--\mathrm{OCO}$ species. The delay in the appearance of $\mathrm{OH}$, observed with a second picosecond laser pulse, is caused by the transient formation of an HOCO complex with significant binding energy relative to both $\mathrm{H}+\mathrm{CO}_{2}$ and $\mathrm{OH}+\mathrm{CO}$ (see boxed insert).

radicals for a rapid bimolecular reaction, they can undergo such a reaction only when they collide. Compared with the timescale of a molecular collision, the time between collisions is usually rather long and there will also be a considerable spread in the times at which prepared radicals react. One way forward is to make use of molecular complexes formed in supersonic molecular beams (Radhakrishnan, G., Buelow, S. \& Wittig, C. J. chem. Phys. 84, 727-738; 1985).

In this way, Zewail and co-workers (Scherer, N. F., Khundkar, L. R., Bernstein, R.B. \& Zewail, A.H. J. chem. Phys. 87, 1451-1453; 1987) have prepared weakly bound complexes of $\mathrm{HI}$ and $\mathrm{CO}$. An ultraviolet laser pulse of about 10 -ps duration photolyses the $\mathrm{HI}$ and impels the $\mathrm{H}$ atom towards the $\mathrm{CO}_{2}$ at considerable velocity (see Fig. 2). Probe laser pulses then measure the appearance of $\mathrm{OH}$ from the reaction: $\mathrm{H}+\mathrm{CO}_{2} \rightarrow$ $\mathrm{OH}+\mathrm{CO}$. The short delay of about $5 \mathrm{ps}$ in the appearance of the $\mathrm{OH}$ confirms that this reaction, and the exothermic reverse reaction between $\mathrm{OH}$ and $\mathrm{CO}$, proceed via the formation of a transitory $\mathrm{HOCO}$ collision complex, a proposal that was made, on indirect evidence, about 10 years ago. By initiating the reaction from a bound complex, this technique also defines a preferred orientation for the reagents, an important parameter not usually available to experimentalists.

It seems likely that the techniques of short-pulse, laser technology and molecular beams have now reached a stage where their combination should allow the nature of transition states, even for direct reactions, to be explored for several reacting systems. If transition-state spectroscopy does become established, then the central theory of chemical kinetics will be subjected to exciting new tests.

Ian W.M. Smith is Professor of Chemistry at the University of Birmingham, PO Box 363. Birmingham B15 2TT, UK.
British IQ

\section{Keeping up with the times}

\author{
Chris Brand
}

Performance on culture-fair IQ tests is improving worldwide (see the News and Views article last month in Nature 328, 110; 1987). Yet does the average gain conceal important differences between nations? James Flynn, the scholarly reporter from New Zealand of the general trend, seems to think so (Psychol. Bull. 101, 171-191; 1987). He especially remarks not only the paucity of British data on IQ (thanks to years of neglect by Britain's educational establishment) but also a tendency for such reported British gains as he could trace to be modest by the standards of other advanced economies. But, coming to the rescue, Richard Lynn and coworkers on page 797 of this issue provide evidence of a rise in IQ in England averaging 0.25 points annually over the past 50 years.

Lynn et al. tested a sample of 1,029 9-11-year-old children from several urban and rural locations in England with the same test that the psychometrician Raymond Cattell had first used in the city of Leicester in 1935 and 1936. Their result is simplicity itself. English children today have a mean IQ of 112 (in comparison with an IQ of 100 in 1935). A minor complication is that the rate of IQ gain may have moderated a little during the Second World War, only to accelerate more steeply in subsequent years. One possible reservation about the study of Lynn et al. is that more low-IQ children of today may be withdrawn into special schools; yet any such change should be roughly counterbalanced by the re-routing of higher-IQ children into private schools because of parental anxieties about falling educational standards in state-run schools.

So what is the meaning of the general IQ rise that has now received its English testimony? Importantly, the 'massive' IQ gain - in the study of Lynn et al., just as in Flynn's data from 14 countries - is principally derived from culture-fair, nonverbal IQ tests that require no particular educational achievement. The possibility is that such gains reflect lowered levels of caution, conscientiousness and conservatism of social attitudes - changes which Lynn has himself recorded elsewhere as increasingly 'extroverted' tendencies in the West since the Second World War (Lynn, R. \& Hampson, S.L. Brit. J. soc. clin. Psychol. 16, 131-138; 1977). For extroversion (or perhaps 'recklessness', indexed as it was in Lynn and Hampson's study by national levels of divorce, cigarette consumption, accidents, crime and illegitimacy) has been rising much faster than has culture-fair IQ: using figures from 1950 onwards, Lynn and Hampson's work suggested gains of around 2 standard deviations over a 30 -year period in advanced countries. This gain should be contrasted with the rise of merely 0.5 of a standard deviation in culture-fair IQ per generation exhibited by English children. Moreover, extroverted and self-reported deliquent tendencies are well known to be associated with somewhat higher culture-fair IQs (for example, Ley, P., Spelman, M.S., Davies, A.D.M. \& Riley, S. Br. J. educ. Psychol. 36, 185-191; 1966) - sometimes correlating as highly as 0.46 with timed performance on such IQ tests (Jensen, A.R. Co-op Project No. 1867, US Dept Health, Education \& Welfare; 1964). By contrast, vocabulary levels, always the best indicator of general intelligence in normal, non-deprived circumstances, have no such association with behavioural disinhibition; and even Flynn does not claim that there has been any great increase in vocabulary scores.

The question that remains in the aftermath of the present work of Lynn et al. is clear. Has the IQ rise occurred mainly on tests of culture-fair IQ that may always have given less conscientious people an unfair advantage? A stress in the classroom on speed of response, imagination and intuition might have improved performance on culture-fair tests, most of which require relatively little by way of articulate judgment or analytical scrupulosity. Certainly, if this were so, it would help explain why conservatism in social attitudes is well known to be negatively correlated with culture-fair IQ (at around -0.40 , even when age is controlled). England's culture-fair IQ rise would then be compatible with its even more rapidly increasing rate (until recently) of crime, irreligiosity, sexual promiscuity and antiauthoritarianism; and also with its world leadership in the field of popular music.

Whether Britain will ever again take the lead in the testing of IQ is a different matter. The study of Lynn et al. shows what can be done even without the help of state funding; but interest will now focus on whether the Scottish Education Department will resolve to examine the intelligence of Scotland's children today with the same verbal IQ test which was first administered to an entire cohort of Scottish children in 1932 and which showed a mere 2 IQ-point gain when it was re-administered in 1947

Chris Brand is in the Department of Psychology, University of Edinburgh, 7 George Square, Edinburgh EH8 $9 J Z, U K$. 